\title{
Use of Iron (II) Salts and Complexes for the Production of Soil Amendments from Organic Solid Wastes
}

\author{
Amerigo Beneduci, ${ }^{1,2}$ Ilaria Costa, ${ }^{2,3}$ and Giuseppe Chidichimo ${ }^{1,2}$ \\ ${ }^{1}$ Department of Chemistry, University of Calabria, Via P. Bucci, Cubo 17/D, 87036 Arcavacata di Rende, Italy \\ ${ }^{2}$ Consorzio TEBAID, Department of Chemistry, University of Calabria, Via P. Bucci, Cubo 17/B, 87036 Arcavacata di Rende, Italy \\ ${ }^{3}$ Biochimica Control S.r.l, 88900 Crotone, Italy
}

Correspondence should be addressed to Giuseppe Chidichimo, chidichi@unical.it

Received 18 October 2011; Revised 24 January 2012; Accepted 31 January 2012

Academic Editor: Licínio M. Gando-Ferreira

Copyright (C) 2012 Amerigo Beneduci et al. This is an open access article distributed under the Creative Commons Attribution License, which permits unrestricted use, distribution, and reproduction in any medium, provided the original work is properly cited.

A method to obtain rapidly stabilized composts for crops from solid organic wastes is evaluated. Here we used a laboratory scale reaction chamber where solid waste treatment was performed under strictly controlled temperature and pressure conditions. The row organic waste was mixed with acid solutions containing iron (II) ions either in the fully hydrated form or in the form of complexes with the diethylentriaminopentaacetic acid. Data from elemental analysis distribution and GC/MS analysis of the polar and non polar dissolved organic matter, clearly showed that Fe(II) ions significantly enhance organic substrate oxidation of the initial solid waste, compared to a material obtained without the addition of the Fe(II) ions to the raw organic matrix. These results suggest that $\mathrm{Fe}$ (II) ions might be involved in a catalytic oxidation pathway that would be activated under the experimental conditions used. The extent of the oxidation process was evaluated by the value of the $\mathrm{C} / \mathrm{N}$ ratio and, qualitatively, by the molecular composition of the dissolved organic matter. After about 6 hours of incubation, dark-brown and dry organic matrices were obtained with $\mathrm{C} / \mathrm{N}$ ratio as low as 12 and a high degree of oxidative decomposition into low-molecular-weight compounds at high oxidation state.

\section{Introduction}

Solid organic waste managing, treatment, and disposal is one of the most important worldwide environmental problems. Among the various options (minimization, recycling, sanitary landfilling, incineration, and composting) composting is one of the most interesting and economically feasible. This is especially true because the produced compost can be used for soil amendment or fertilizer when the organic waste does not contain pollutants such as heavy metals. The composting process is defined as "the biological decomposition of biodegradable solid waste under controlled predominantly aerobic conditions to a state that is sufficiently stable for nuisance-free storage and handling and is satisfactorily matured for safe use in agriculture" [1]. In this process, the raw organic material is progressively broken down by a succession of populations of living organism at different stages of the decomposition process (mesophilic, thermophilic, and maturation stages) [2]. Micro- and macroflora are key process factors controlling the composting process. Other key factors are temperature, $\mathrm{pH}$, moisture content, and aeration as well as the chemical and physical availability of the nutrients in the organic waste, respectively, determined by the molecules vulnerability to microbes attack and by the particle size.

The most limiting problem affecting the full exploitation of this technology is its intrinsic slowness related to the natural biodegradation process that takes more than 3 months to go through. In addition, another disadvantage is due to the foul odor produced, particularly during the mesophilic stage of the process. Recently, several processes were advanced in order to overcome the above limits. Common feature of some of them is to dry the organic waste after a first sterilization stage made either by a boilripening treatment of the organic waste at high pressure (15$25 \mathrm{~atm})$ and temperature $\left(150-250^{\circ} \mathrm{C}\right)$ [3] or by addition of 
lime so as to increase the $\mathrm{pH}$ to values under which aerobic fermentation is inhibited [4]. The drying process stabilizes the organic material but, in the absence of a fermentation stage, most of the organic material cannot be broken down to small molecules and, therefore, the compost cannot be stored for long periods of time under nonsterile conditions. This is partly overcome by a more complicated two-stage process: (1) fermentation and (2) drying [5, 6]. The fermentation stage was shown to be improved by addition of strong oxidizing agents such as metal alkali peroxides and chlorates whose reduced products are retained in the final compost [6].

The aim of the present work is to evaluate the catalytic performances of iron (II)-based catalysts in the composting process of solid organic wastes. Ferrous ions, when mixed with hydrogen peroxide, form a very effective oxidizing agent known as Fenton reagent [7-9]. It has been extensively used as a method for the oxidation of organic pollutants of different molecular origin in industrial wastewater [920]. Even though the mechanism of the Fenton reaction has not yet been fully clarified, two main mechanisms have been advanced [8, 21-23]: a radical one, involving the hydroxyl radical as reactive oxygen species, and a nonradical one, involving the formation of an intermediated iron (IV) complex. The hypothesis undergoing the present project is that an iron (II) overload into the organic material may activate Fenton chemistry or Fenton-like chemistry reactions in combination with endogenous hydrogen peroxide always produced in aerobic conditions by microorganisms [21] responsible for the early stages of the biodegradation process.

\section{Materials and Methods}

2.1. Organic Solid Waste and Treatment. Raw organic material (OM) was derived from restaurant refuses containing pasta, pizza, fruit (pineapple, apple, and melon), potatoes, vegetables, and eggs. OM was minced with a rotating blade mill provided with a $10 \mathrm{~mm}$ sieve and introduced into the reaction chamber where temperature and pressure were under control. The chamber was a 25-liter steel cylinder provided with an axial blade stirrer. A pressure gradient of about 0.01 bars was kept between the cylinder extremities in order to allow a constant air circulation. The temperature of the chamber could be regulated by an external strip resistor. The ferrous ion-based catalysts were added to the organic waste and the reaction mixture was continuously stirred. Experiments have been performed on $12 \mathrm{Kg}$ of solid waste having the same initial composition. In some experiments, $1 \mathrm{~kg}$ of soil containing inert inorganic material (IM) made of oxides of $\mathrm{Ca}, \mathrm{Al}, \mathrm{Fe}$, and $\mathrm{Si}$ and several other microelements present in traces $(\sim 1 \mathrm{ppb})$ such as $\mathrm{Cu}^{++}, \mathrm{Zn}^{++}, \mathrm{Co}^{++}, \mathrm{Mn}^{++}$, $\mathrm{Pb}^{++}$, and $\mathrm{Sr}^{++}$, was mixed with $\mathrm{OM}$. In order to dry and stabilize the organic mass, the mixture was heated at $55^{\circ} \mathrm{C}$ under an air constant flow rate of 20 liters/s, ensuring its slow drying. The initial moisture content was about $72 \%$, and, after 6 hours of treatment, a final moisture content of about $15 \%$ was obtained. The stability of the composts produced by the above procedure was evaluated by means of their odor and color properties and by their C/N ratio [24].
These properties were monitored for a period of up to six months on composts stored in a dry environment.

In addition, compost stability was qualitatively estimated by the degree of the oxidative decomposition process evaluated by GC/MS analysis of the polar and nonpolar dissolved organic matter (see below).

2.2. Catalyst. Two different solutions of iron (II) catalyst were studied: a $15 \%(\mathrm{w} / \mathrm{w})$ solution of $\mathrm{FeSO}_{4}$ acidified at $\mathrm{pH}$ 3.8 with sulfuric acid (solution A) and a $6 \%(\mathrm{w} / \mathrm{w})$ solution of the $\mathrm{Fe}(\mathrm{II})$-diethylenetriaminepentaacetic acid complexes (Fe(II)-DTPA) at pH 5 (solution B) [25].

2.3. Elemental Analysis: Determination of Total Organic Carbon (TOC) by the Official Method UNI EN 13137:2002. TOC was determined by high temperature combustion of the sample $\left(T \geq 900^{\circ} \mathrm{C}\right)$, after a digestion process, in a SHIMADZU instrument model SM $5000 \mathrm{~A}$. This equipment can analyze liquid sample too, but not water solutions.

Determination of $\mathrm{S}$ and $\mathrm{Cl}$ percentages was performed by the following procedure: the sample was oxidized by combustion into a bomb containing oxygen under pressure, according to the method EPA 50501994 (preparation) + EPA 9056A 2007 (analysis). After complete sample digestion, the $\% \mathrm{Cl}$ and \% S were estimated by analyzing water produced using the ion chromatography method. The instrument used was a LECO AC500 Mahler bomb calorimeter. It completely burns the sample in a total oxidative digestion process.

The remaining elements $(\mathrm{O}, \mathrm{H}, \mathrm{N})$ were determined by combustion with the elemental analyzer THERMO ELECTRON NC Soil Flash EA1112, according to the method UNI EN 15407:2006. This instrument is a two-furnace system: an oxidative and a reductive one. Analytes (in gaseous state) are determined by passing each one in a thermoconductivity detector (TCD) and by the conductivity difference between a reference carrier gas and the sample gas; it is possible to evaluate the concentration of $\mathrm{C}, \mathrm{H}$, and $\mathrm{N}$ in terms of their percentage.

2.4. GC/MS Analysis. From a representative amount of OM $(\sim 20 \mathrm{~g})$ the polar and nonpolar soluble fractions were extracted, respectively, in methanol and n-hexane. Extraction was performed by an ASE 100 DIONEX automatic extractor at $100^{\circ} \mathrm{C}$ under nitrogen atmosphere at high pressure. 1 microliter of the dissolved organic matter was injected, without purification, into the GC/MS system for analysis. In order to increase the sensitivity of the analysis and to detect a larger number of degradation products, the dissolved organic matter was concentrated to $1 / 3$ of the original volume and 1 microliter used for GC/MS characterization. All analyses were performed with a GC VARIAN model 3800 coupled with a triple quadrupole mass detector VARIAN model 320-MS TQ. The column used was a VARIAN model "Factor Four" VF-5 ms capillary column; $30 \mathrm{~m} ; 0.25 \mathrm{~mm} ; 0.25 \mu \mathrm{m}$.

Mass spectra were collected as raw data by EI mode (electron impact) with collision energy of $70 \mathrm{eV}$. All peaks were identified by comparison with a NIST certified library 
TABLE 1: Elemental percentages (organic mass) of the composts under different biodegradation conditions.

\begin{tabular}{|c|c|c|c|c|c|c|}
\hline \multirow[b]{2}{*}{ Elemental \% } & \multirow[b]{2}{*}{$\mathrm{OM}$} & \multicolumn{4}{|c|}{ Compost } & \multirow{2}{*}{$\begin{array}{c}\text { Commercial compost } \\
\text { C5 } \\
\end{array}$} \\
\hline & & $\mathrm{C} 1$ & $\mathrm{C} 2$ & $\mathrm{C} 3$ & $\mathrm{C} 4$ & \\
\hline $\mathrm{C}(\mathrm{TOC})$ & 58.86 & 50.35 & 47.29 & 46.52 & 39.01 & 52.0 \\
\hline $\mathrm{H}$ & 7.10 & 5.99 & 6.09 & 6.35 & 5.02 & 5.5 \\
\hline $\mathrm{N}$ & 4.50 & 2.60 & 2.53 & 2.67 & 3.20 & 2.5 \\
\hline $\mathrm{O}$ & 28.42 & 38.5 & 44.55 & 43.37 & 52.20 & 38.8 \\
\hline $\mathrm{Cl}$ & 0.88 & 0.89 & 0.65 & 0.89 & 0.87 & 1.0 \\
\hline S & 0.24 & 1.61 & 0.25 & 0.20 & 0.18 & 0.2 \\
\hline $\mathrm{C} / \mathrm{N}$ & 31 & 19 & 19 & 17 & 12 & 21 \\
\hline $\mathrm{OM}(\mathrm{Kg})$ & & 12 & 12 & 12 & 12 & \\
\hline $\mathrm{Fe}(\mathrm{II})$ solution type & & l & A & A & $\mathrm{B}$ & 1 \\
\hline $\mathrm{Fe}(\mathrm{II})$ solution (g) & & l & 250 & 250 & 250 & I \\
\hline $\mathrm{IM}(\mathrm{Kg})$ & & 1 & 1 & 1 & I & \\
\hline
\end{tabular}

${ }^{*}$ C1-5: compost 1-5.

of mass spectra (acquired at $70 \mathrm{eV}$ ) as the most probable component in the mixture.

\subsubsection{Acquisition Method for Liquid Mode (Determination} of Extractable Components, Polar and Apolar). Mass range: 50-2000 uma; EDR system: active; delay: 4 minutes; source temperature: $250^{\circ} \mathrm{C}$; transfer line temperature: $300^{\circ} \mathrm{C}$; dwell time: $0,5 \mathrm{sec}$; injection mode: splitless; injector temp.: $220^{\circ} \mathrm{C}$; inj. volume: $1 \mu \mathrm{L}$; carrier flow: $1 \mathrm{~mL} / \mathrm{min}$ helium; oven program: init.: $40^{\circ} \mathrm{C}$; hold $2 \mathrm{~min}$.; $5^{\circ} \mathrm{C} / \min 270^{\circ} \mathrm{C}$; hold 20 minutes.

2.4.2. Acquisition Method for Head Space Mode (H. S.) (Determination of Volatile and Light Components). Mass range: 50-500 uma; EDR system: active; delay: 0 minutes; source temperature: $250^{\circ} \mathrm{C}$; transfer line temperature: $300^{\circ} \mathrm{C}$; dwell time: $0,5 \mathrm{sec}$; Injection mode: splitless; injector temp.: $100^{\circ} \mathrm{C}$; inj. volume: $2500 \mu \mathrm{L}$; carrier flow: $1 \mathrm{~mL} / \mathrm{min}$ helium; oven program: init.: $45^{\circ} \mathrm{C}$; hold $2 \mathrm{~min} . ; 5^{\circ} \mathrm{C} / \min 250^{\circ} \mathrm{C}$; hold 5 minutes.

\section{Results}

3.1. Elemental Analysis. Table 1 shows the elemental distribution of the row organic mass (OM) and that of the organic mass of the various composts obtained from $\mathrm{OM}$ under different biodegradation conditions. They are compared with those of a typical compost used as fertilizer (C5) as well as with those of a compost obtained by drying the row organic waste when mixed with the IM (C1). It can be seen that in all of the composts $\mathrm{C} 1-\mathrm{C} 4$ the percentages of $\mathrm{C}, \mathrm{H}$, and $\mathrm{N}$ are lower than those found in the initial organic waste $(\mathrm{OM})$. This reduction is mainly due to a significant increase of the percentage of oxygen in all of the composts examined. This increase becomes very large for the compost C4 that exhibited about a $45 \%$ increase of the \% of oxygen atoms relative to the untreated waste. These data unequivocally suggest that during the organic waste treatment, extensive oxidative biodegradation processes occur. Another interesting data is the significant reduction of the $\mathrm{C} / \mathrm{N}$ ratio that gradually decreases from $\mathrm{OM}$ that has the largest value equal to 31 to $\mathrm{C} 4$ for which this ratio becomes 12 .

Significant differences in the elemental distribution were also observed between the composts obtained with the $\mathrm{Fe}$ (II) containing solutions $(\mathrm{C} 2-\mathrm{C} 4)$ and without them $(\mathrm{C} 1)$. In particular, it is worth to note that, when the $\mathrm{Fe}$ (II) ions were present, the increase of the percentage of oxygen was higher than in their absence, when the ferrous ions were added to the waste either in the fully hydrated form (solution A) or in a complex with the diethylenetriaminepentaacetic acid (solution B). This suggests that $\mathrm{Fe}(\mathrm{II})$ ion plays a major role in the biodegradation process. However, it can be further noted, from Table 1, that the oxidative biodegradation process appears to be more efficient when the ferrous ion complex is used. Indeed, the compost $\mathrm{C} 4$ had the highest percentage of oxygen and the lowest $\mathrm{C} / \mathrm{N}$ ratio.

The composts prepared in the presence of the iron (II) catalyst were dark-brown, dry, granulous (almost $1 \mathrm{~mm}$ grains), without smell. Odor and color properties of $\mathrm{C} 4$ as well as its $\mathrm{C} / \mathrm{N}$ ratio and its molecular composition were monitored for up to 6 months. After this period we did not observe significant changes of the above parameters, indicating that this compost was stable. In contrast, $\mathrm{C} 1$ was not stable and after few days from the treatment it was covered by molds and gave a foul odor characteristic of volatile mercaptans.

3.2. GC/MS Results. Due to the very interesting elemental distribution differences between $\mathrm{C} 1$ and $\mathrm{C} 4$, we deeply studied the molecular composition of these two materials by means of the GC/MS analysis. Figures 1 and 2 show the chromatograms of the nonpolar and polar dissolved organic matter, respectively, for C1 (A) and C4 (B). All the peaks in the chromatograms were identified by the corresponding mass fragmentation spectra. Tables 2 to 4 summarize the classes of functional groups found in the above organic matters. Major differences in the chromatograms of the two composts can be seen at low retention times and on the 
TABle 2: Molecular composition of the low-molecular-weight fraction of the extracts from composts C1 and C4. Hydrocarbons, alcohols, thiols, ethers, thioethers, sulfones, and amines.

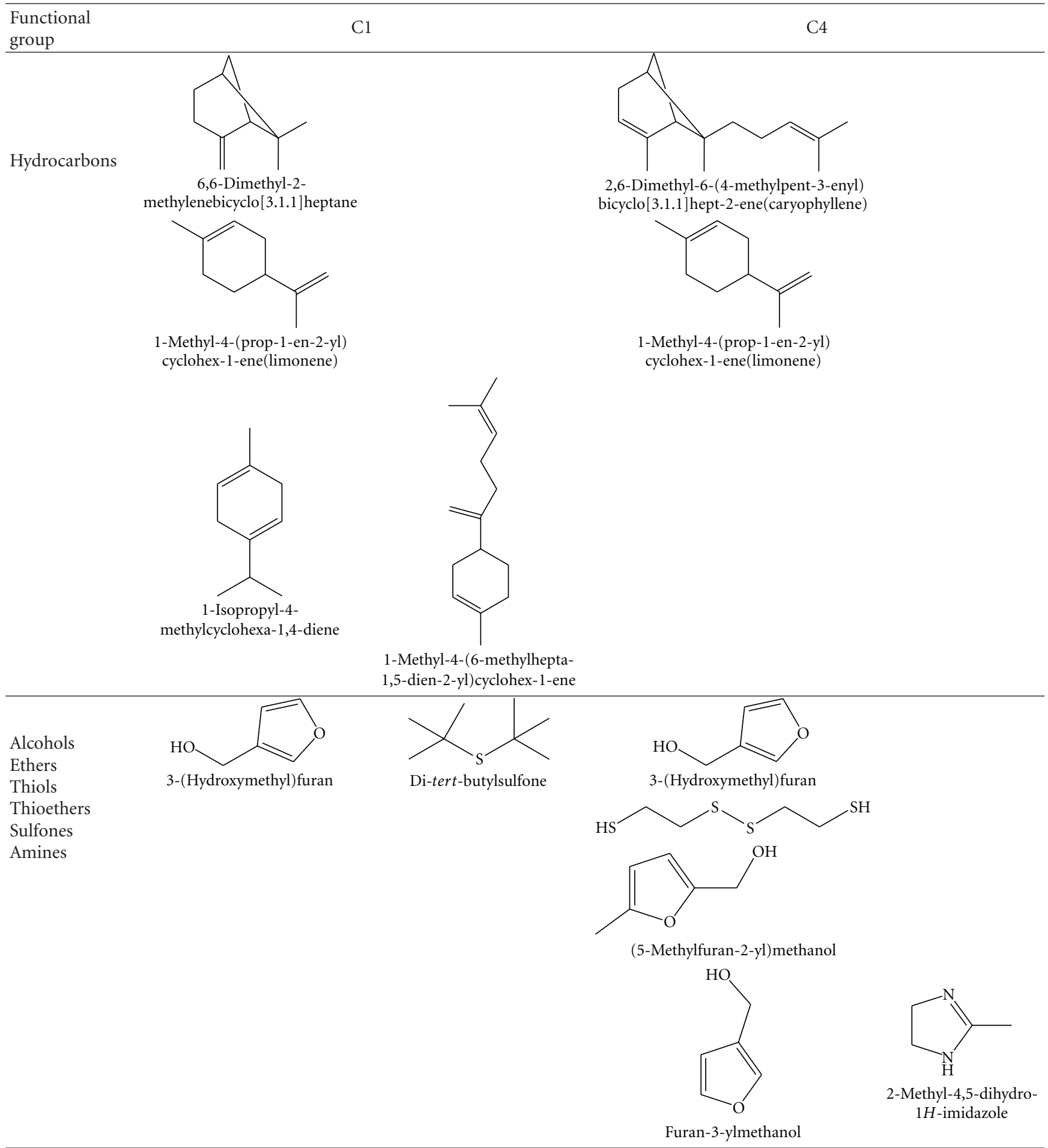

extracts as such without concentration pretreatment. This is to be attributed to significant differences in the lowmolecular-weight content of the two extracts. Actually, the identification of the light fraction of the extracts by MS revealed that $\mathrm{C} 4$ was reached in compounds at high oxidation state such as aldehydes, ketones, and cyclic esters (Tables 2, 3, and 4). These were detected to a lower extent in the extracts of $\mathrm{C} 1$ too, but it was mainly composed by hydrocarbons, alcohols, ethers, and thioethers (Tables 2-4).

The high-molecular-weight fractions of the C1 and C4 extracts were very similar and contained long-chain (C10C23) fatty acids and their corresponding methyl and ethyl 
TABLe 3: Molecular composition of the low-molecular-weight fraction of the extracts from composts C1 and C4. Aldehydes and ketones.

Functional group

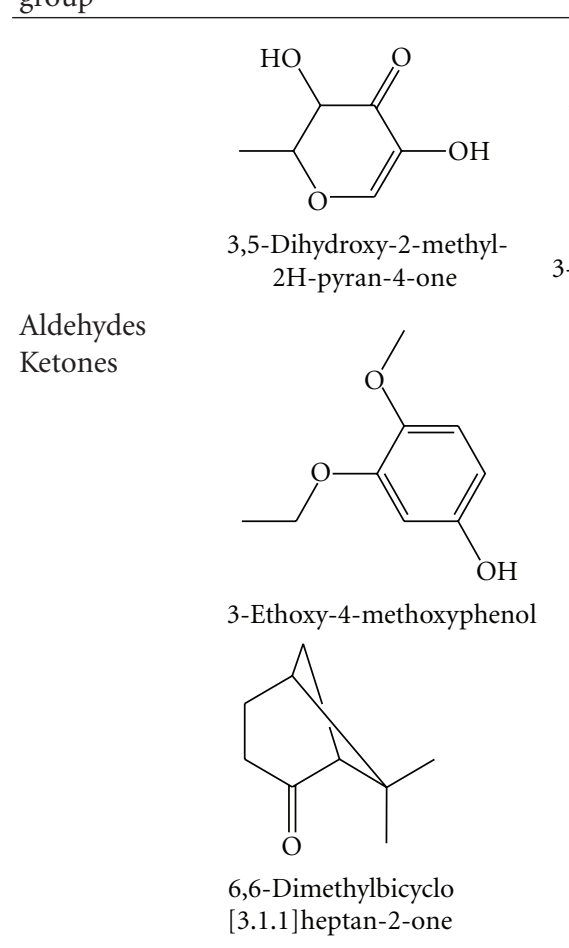

$\mathrm{C} 1$
$\mathrm{C} 4$
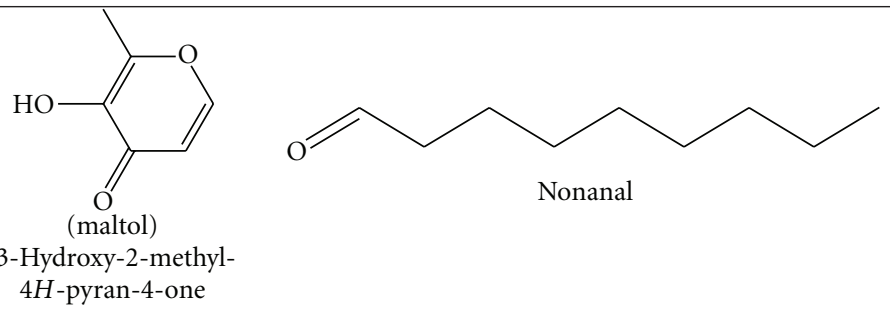

4H-pyran-4-one

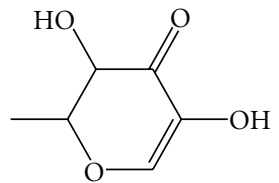

3,5-Dihydroxy-2-methyl-2H-pyran-4-one

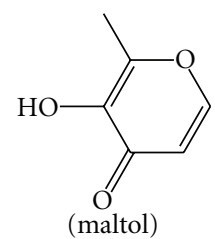

3-Hydroxy-2-methyl-

$4 H$-pyran-4-one

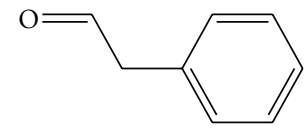

Benzeneacetaldehyde

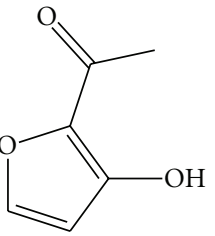

1-(3-Hydroxyfuran

-2-yl)ethanone

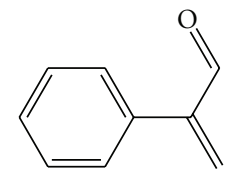<smiles>COc1ccccc1O</smiles>

2-Phenylpropenal 2-Methoxyphenol<smiles>COc1cc(C=O)ccc1O</smiles>

4-Hydroxy-3-methoxybenzaldehyde<smiles>O=Cc1ncc[nH]1</smiles>

$1 H$-Imidazole-2-carbaldehyde

$\mathrm{O}$<smiles>C=C1C=CCC(=O)O1</smiles> 


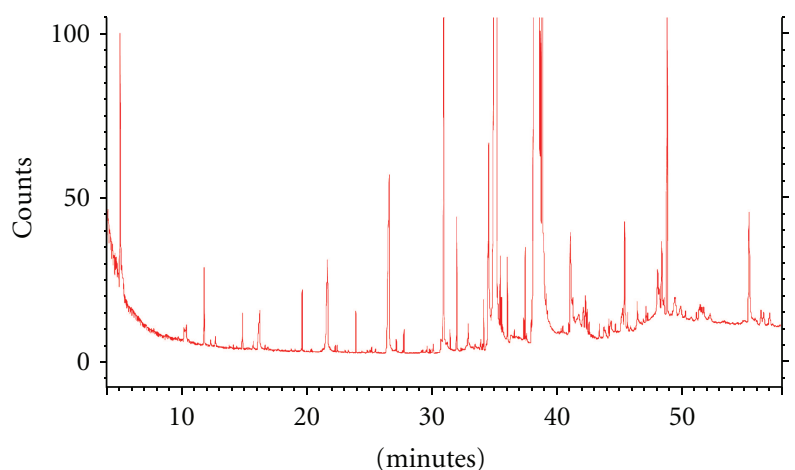

(a)

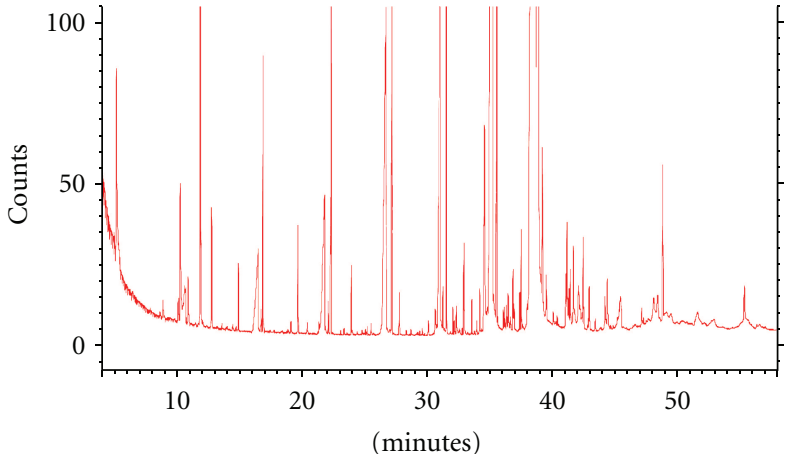

(b)

FIGURE 1: GC chromatograms of the non polar dissolved organic matter extracted in n-hexane from composts C1 (a) and C4 (b). Some of the classes of the functional groups are reported here as a function of the retention time (minutes): up to $32^{\prime}$ we have terpene, decanoic, dodecanoic, and tetradecanoic acids, and tetradecenal. The remaining peaks were attributed to C16-C18 fatty acids and relative esters. At $50^{\prime}$ squalene was found. It can be seen that the region at low retention times in chromatogram (b) is more crowded than in (a).

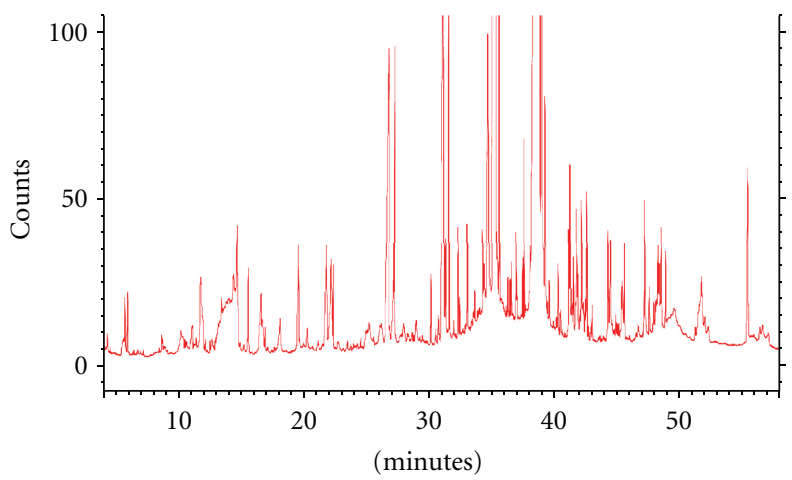

(a)

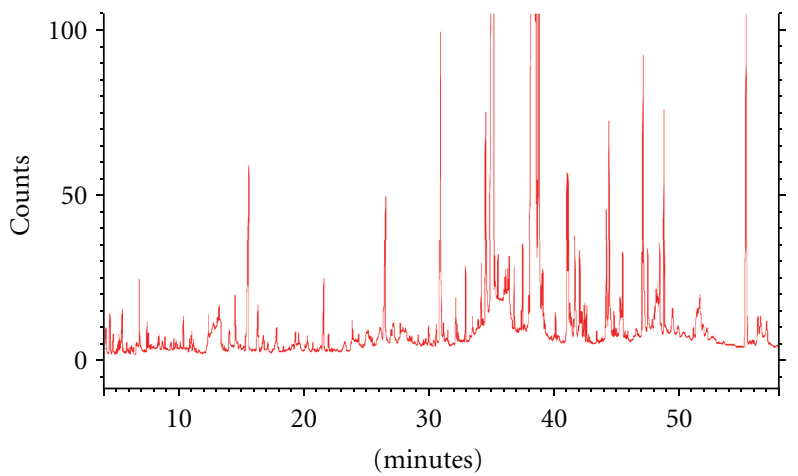

(b)

Figure 2: GC chromatograms of the extracts in methanol of the composts C1 (a) and C4 (b). Some of the classes of the functional groups are reported here as a function of the retention time (minutes): up to $20^{\prime}$ we have low-molecular-weight ketones, aldehydes, and polyalcohols and at $20^{\prime}-40^{\prime}$ fatty acid and fatty acid esters. It can be seen that the region at low retention times in chromatogram (b) is more crowded than in (a).

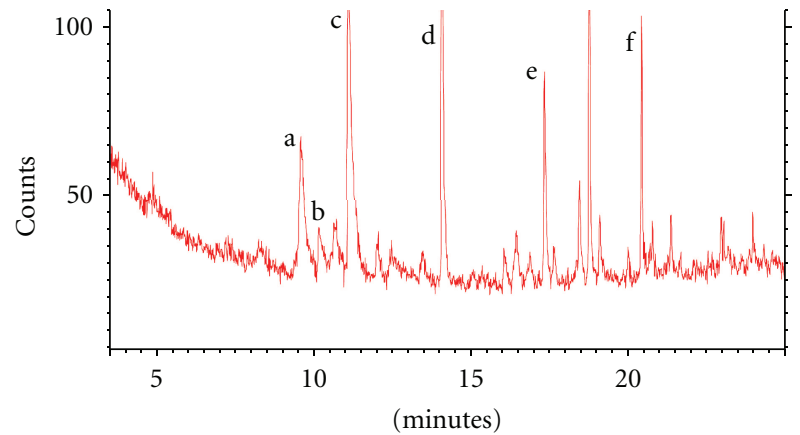

FIGURE 3: Headspace GC analysis of the volatile fraction obtained from compost $\mathrm{C} 1$. a: light terpene; b: butyrate; c: limonene; d: propanethiol; e: 2 -decenale; f: 2 -undecenale.

esters as well as cholesterol (3 beta-cholest-5-en-3-ol) and high-molecular-weight terpenes like squalene.
These data strongly support the quantitative results on the elemental distribution of the various composts (Table 1). Indeed, the high relative amount of oxygen-rich low-molecular-weight compounds at high oxidation state determined in C4 is in very good agreement with the high percentage of elemental oxygen found in this compost.

The analysis by headspace chromatography coupled to MS essentially confirmed the data reported in Table 2 for the compost $\mathrm{C} 4$ but revealed the presence of cyclic hydrocarbons, butyrate, and low-molecular-weight thiols responsible for the rancid smell of $\mathrm{C} 1$ (Figure 3).

\section{Discussion}

The data presented here clearly shows that if the organic waste is treated in a reactor under the temperature and pressure conditions here described (see "Section 2"), the addition of $\mathrm{Fe}(\mathrm{II})$ ions improves the oxidative degradation processes of the waste and leads, in a few hours, to organic matrices characterized by low-molecular-weight compounds 
TABle 4: Molecular composition of the low-molecular-weight fraction of the extracts from composts C1 and C4. Carboxylic acids, esters, and amides.

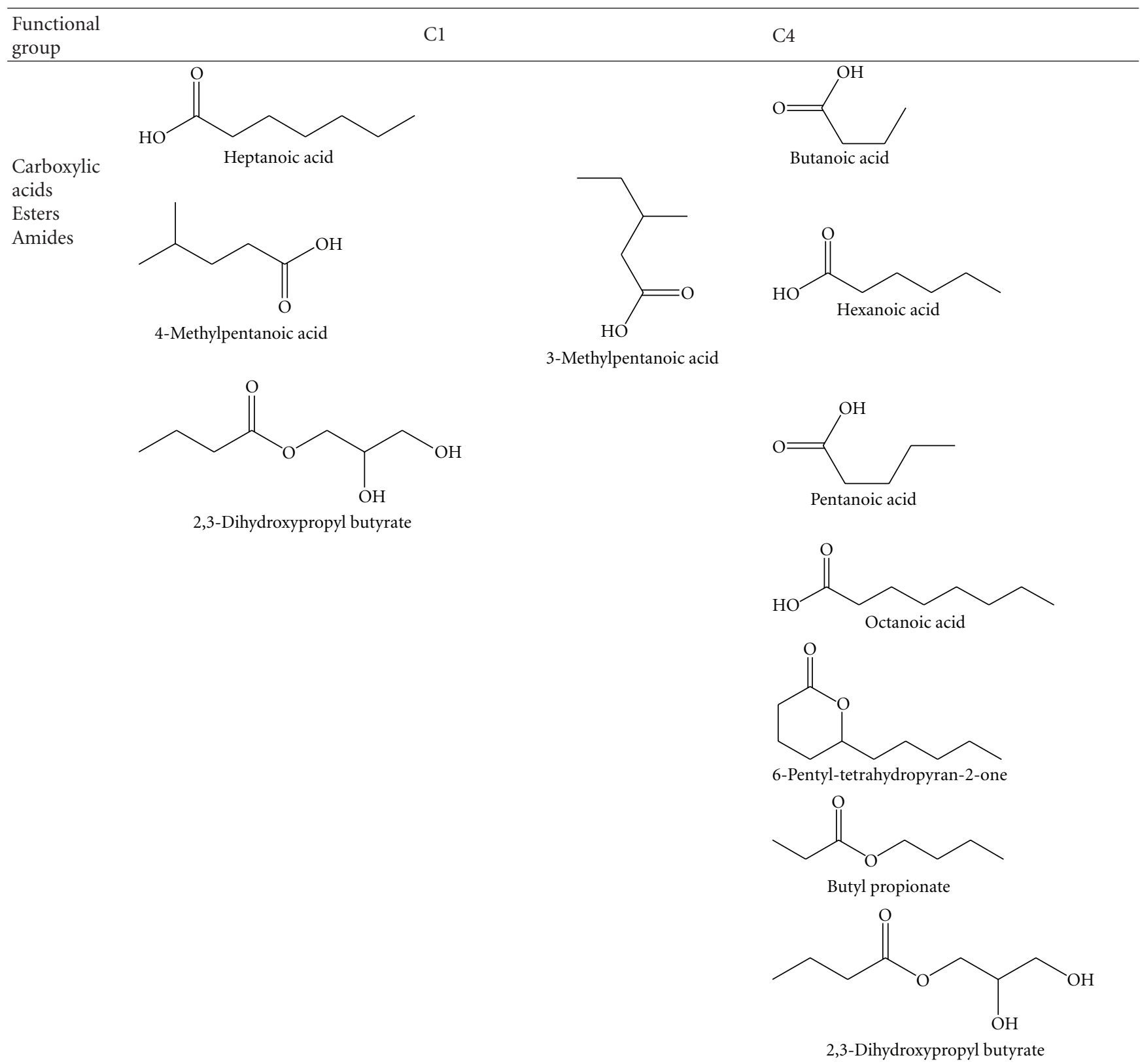

at high oxidation state, like acids and esters. In addition, composts obtained by this method exhibited low $\mathrm{C} / \mathrm{N}$ ratios and were stable at least from the point of view of their odor and color properties and their molecular composition. Even if further studies are required to evaluate the usefulness of the obtained composts in agriculture practice, nonetheless, the treatment of organic solid waste here proposed seems to be very promising for many potential applications (soil amendment, fuels, etc.).

The results discussed above suggest that ferrous ion plays a significant role in the oxidative process of the raw organic material. It is therefore necessary to hypothesize that this ion is involved in a reaction mechanism that may significantly contribute to enhance the oxidation process. One of the most probable mechanisms is a catalytic process known as Fenton reaction in which the highly reactive oxygen species hydroxyl radical $\mathrm{HO}^{\bullet}$ and/or ferryl ion $\left[\mathrm{Fe}^{4+}\left(\mathrm{OH}^{-}\right)_{2}\right]_{\mathrm{aq}}$ are produced [9, 21-23]. Under the assumption that the Fenton reaction proceeds via an inner-sphere two-electron-transfer mechanism [22], the following simplified reaction scheme may be suggested for organic substrates oxidation by Fenton reaction:

$$
\mathrm{Fe}_{\mathrm{aq}}^{2+}+\mathrm{H}_{2} \mathrm{O}_{2} \longrightarrow \mathrm{Fe}\left(\mathrm{H}_{2} \mathrm{O}_{2}\right)_{\mathrm{aq}}{ }^{2+} \longrightarrow\left[\mathrm{Fe}^{4+}\left(\mathrm{OH}^{-}\right)_{2}\right]_{\mathrm{aq}} \text {. }
$$


The intermediate iron (IV) complex may oxidize the organic substrates. Alternatively, it could react further, leading to the formation of a free hydroxyl radical and $\mathrm{Fe}_{\mathrm{aq}}^{3+}$ :

$$
\left[\mathrm{Fe}^{4+}\left(\mathrm{OH}^{-}\right)_{2}\right]_{\mathrm{aq}} \longrightarrow \mathrm{Fe}_{\mathrm{aq}}^{3+}+\mathrm{OH}^{-}+\mathrm{OH}^{\bullet} .
$$

The hydroxyl radical that takes place in step (2) could react with the organic substrate leading to its oxidation.

The Fe(III) formed in the oxidation steps is reduced, under acidic conditions, leading again to ferrous ion that can reenter in the oxidative Fenton cycle [22]:

$$
\begin{gathered}
\mathrm{Fe}_{\mathrm{aq}}^{3+}+\mathrm{H}_{2} \mathrm{O}_{2} \stackrel{\mathrm{H}^{+}}{\longrightarrow} \mathrm{Fe}_{\mathrm{aq}}^{2+}+\mathrm{OH}_{2}^{\cdot} \\
\mathrm{Fe}_{\mathrm{aq}}^{3+}+\mathrm{OH}_{2}^{\bullet} \longrightarrow \mathrm{Fe}_{\mathrm{aq}}^{2+}+\mathrm{O}_{2}+2 \mathrm{H}^{+} .
\end{gathered}
$$

Even though reaction (3) is slow, reaction (4) is irreversible and the sequence is therefore shifted to the right favoring the reduction of $\mathrm{Fe}_{\mathrm{aq}}^{3+}$ to $\mathrm{Fe}_{\mathrm{aq}}^{2+}$ and the oxidation of $\mathrm{H}_{2} \mathrm{O}_{2}$ to $\mathrm{O}_{2}$.

The hypothesis that Fenton chemistry is involved in the biodegradation of the organic waste appears to be reasonable if we take into account that the presence of a variety of aerobic microorganisms populates the organic material that might be the endogenous source of hydrogen peroxide through the mechanism of molecular oxygen reduction. In this process, which is ubiquitous in aerobic systems, the molecular oxygen can undergo an initial one-electron reduction by an electron donor to form the superoxide anion $\mathrm{O}_{2}^{*-}$ that is subsequently converted to $\mathrm{H}_{2} \mathrm{O}_{2}$.

\section{Conclusions}

Here we have treated solid organic wastes into a $25 \mathrm{~L}$ reaction chamber under strictly controlled temperature and pressure conditions and we have evaluated the effects of iron (II) ion on the oxidative decomposition process of the solid waste. We have found that $\mathrm{Fe}(\mathrm{II})$ ion enhances such a process especially when it is introduced into the raw organic matter in form of complexes of the ethylenetriaminepentaacetic acid. This observation is very interesting and deserves further studies. After 6 hours of waste treatment, we observed a high degree of oxidative decomposition revealed by GC/MS analysis of the polar and non polar dissolved organic matter that led to composts with $\mathrm{C} / \mathrm{N}$ ratios as low as 12 , compared to an initial value of 31 . In addition, the composts obtained exhibited dark-brown color they did not emanate smell and have humidity of the order of $15 \%$. The product obtained in the present work cannot be considered as a conventional compost. At the actual stage of investigation, we only claim to have transformed the original organic waste material into a stabilized organic matrix. We mean in this case that the material does not go, at least within 6 months, in further biochemical transformation when stored under dry conditions. The property of the material as a soil fertilizer needs to be inquired by determining the further biochemical and chemical transformations it will undergo when added to soil. In particular, its influence on the vegetable growth needs to be determined. Studies are in progress in these directions.

\section{References}

[1] UNEP, "Composting," in Solid Waste Management, United Nation Environmental Program, Ed., vol. 1, part 2, chapter 8, pp. 198-235, 2005.

[2] M. de Bertoldi, G. Vallini, and A. Pera, "The biology of composting: a review," Waste Management and Research, vol. 1, no. 2, pp. 157-176, 1983.

[3] M. Kosaku, "Method of manufacturing full-ripe fertilizer using organic waste," JP2003055078 (A), 2003.

[4] Z. Xianjin, X. Weijian, and S. Jinghu, Production of a natural catalyst by drying of natural organic waste, CN2003-01-08.

[5] L. M. Hyoung, "Method for producing organic fertilizer using organic wastes and inorganic materials and devices used therefor," KR20010091641 (A), 2001.

[6] T. Hitoshi, "Chemical-physical process for fertilizer production from organic waste and production plant," JP5295376, 1993.

[7] H. J. H. Fenton, "Oxidation of tartaric acid in presence of iron," Journal of the Chemical Society, Transactions, vol. 65, pp. 899-910, 1894.

[8] H. B. Dunford, "Oxidations of iron(II)/(III) by hydrogen peroxide: from aquo to enzyme," Coordination Chemistry Reviews, vol. 233-234, pp. 311-318, 2002.

[9] K. Barbusiński, "Fenton reaction. Controversy concerning the chemistry," Ecological Chemistry and Engineering S, vol. 16, no. 3, pp. 347-358, 2009.

[10] C. P. Huang, C. Dong, and Z. Tang, "Advanced chemical oxidation: its present role and potential future in hazardous waste treatment," Waste Management, vol. 13, no. 5-7, pp. 361-377, 1993.

[11] E. Neyens and J. Baeyens, "A review of classic Fenton's peroxidation as an advanced oxidation technique," Journal of Hazardous Materials, vol. 98, no. 1-3, pp. 33-50, 2003.

[12] I. Casero, D. Sicilia, S. Rubio, and D. Pérez-Bendito, "Chemical degradation of aromatic amines by Fenton's reagent," Water Research, vol. 31, no. 8, pp. 1985-1995, 1997.

[13] W. G. Kuo, "Decolorizing dye wastewater with Fenton's reagent," Water Research, vol. 26, no. 7, pp. 881-886, 1992.

[14] S. Nam, V. Renganathan, and P. G. Tratnyek, "Substituent effects on azo dye oxidation by the Fe ${ }^{\mathrm{III}}$-EDTA- $\mathrm{H}_{2} \mathrm{O}_{2}$ system," Chemosphere, vol. 45, no. 1, pp. 59-65, 2001.

[15] K. Barbusiński, "The modified Fenton process for decolorization of dye wastewater," Polish Journal of Environmental Studies, vol. 14, no. 3, pp. 281-285, 2005.

[16] P. L. Huston and J. J. Pignatello, "Degradation of selected pesticide active ingredients and commercial formulations in water by the photo-assisted Fenton reaction," Water Research, vol. 33, no. 5, pp. 1238-1246, 1999.

[17] K. Barbusiński and K. Filipek, "Use of Fenton's reagent for removal of pesticides from industrial wastewater," Polish Journal of Environmental Studies, vol. 10, no. 4, pp. 207-212, 2001.

[18] K. Ikehata and M. G. El-Din, "Aqueous pesticide degradation by hydrogen peroxide/ultraviolet irradiation and Fentontype advanced oxidation processes: a review," Journal of Environmental Engineering and Science, vol. 5, no. 2, pp. 81135, 2006.

[19] S. H. Lin, C. M. Lin, and H. G. Leu, "Operating characteristics and kinetic studies of surfactant wastewater treatment by Fenton oxidation," Water Research, vol. 33, no. 7, pp. 17351741, 1999.

[20] M. Kitis, C. D. Adams, and G. T. Daigger, "The effects of Fenton's reagent pretreatement on the biodegradability of 
nonionic surfactants," Water Research, vol. 33, no. 11, pp. 2561-2568, 1999.

[21] J. Prousek, "Fenton chemistry in biology and medicine," Pure and Applied Chemistry, vol. 79, no. 12, pp. 2325-2338, 2007.

[22] S. H. Bossmann, E. Oliveros, S. Göb et al., "New evidence against hydroxyl radicals as reactive intermediates in the thermal and photochemically enhanced fenton reactions," Journal of Physical Chemistry A, vol. 102, no. 28, pp. 55425550, 1998.

[23] M. D. Paciolla, G. Davies, and S. A. Jansen, "Generation of hydroxyl radicals from metal-loaded humic acids," Environmental Science and Technology, vol. 33, no. 11, pp. 1814-1818, 1999.

[24] M. P. Bernal, C. Paredes, M. A. Sanchez-Monedero, and J. Cegarra, "Maturity and stability parameters of composts prepared with a wide range of organic wastes," Bioresource Technology, vol. 63, no. 1, pp. 91-99, 1998.

[25] J. Vandegaer, S. Chaberek, and A. E. Frost, "Iron chelates of diethylenetriaminepentaacetic acid," Journal of Inorganic and Nuclear Chemistry, vol. 11, no. 3, pp. 210-221, 1959. 

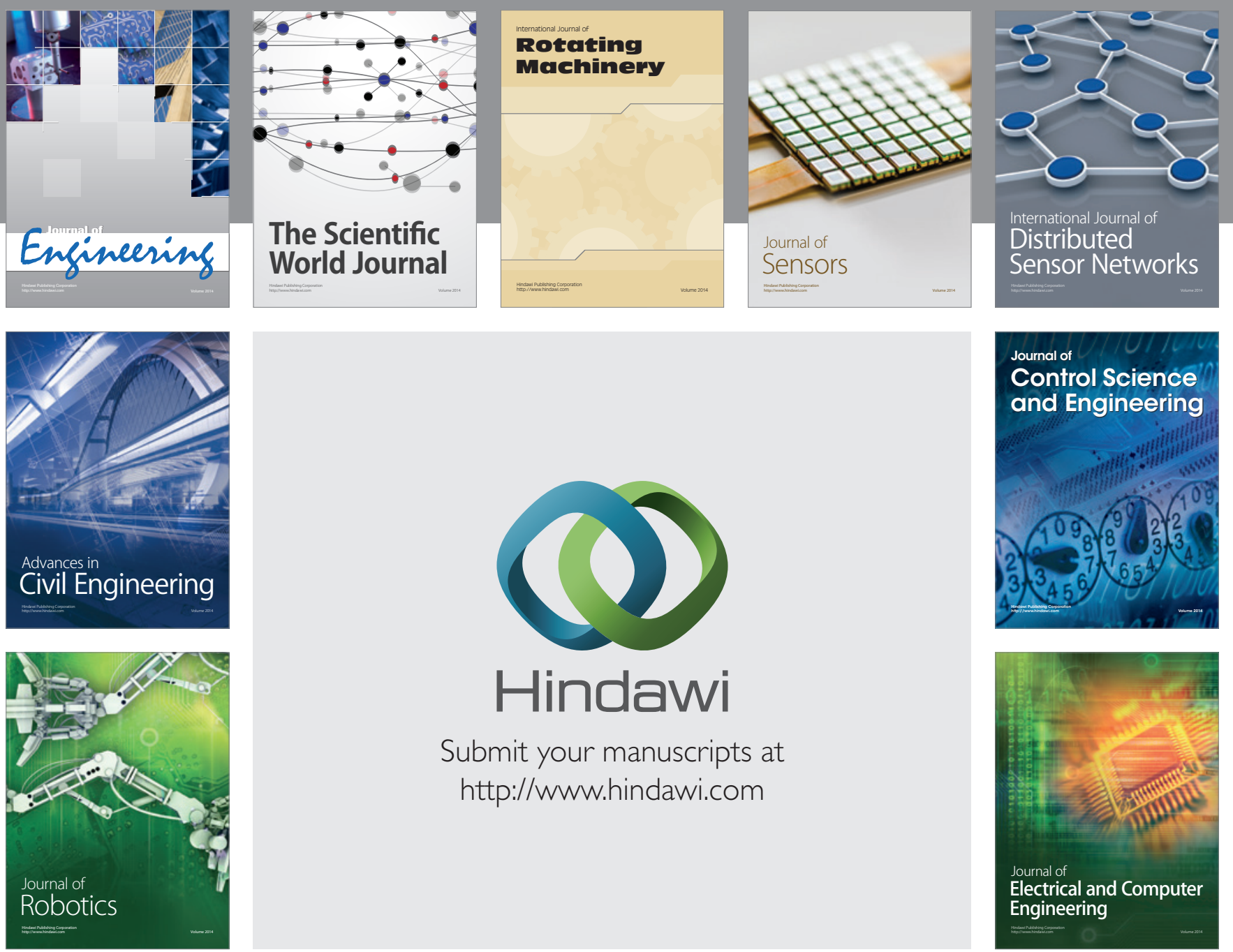

Submit your manuscripts at

http://www.hindawi.com
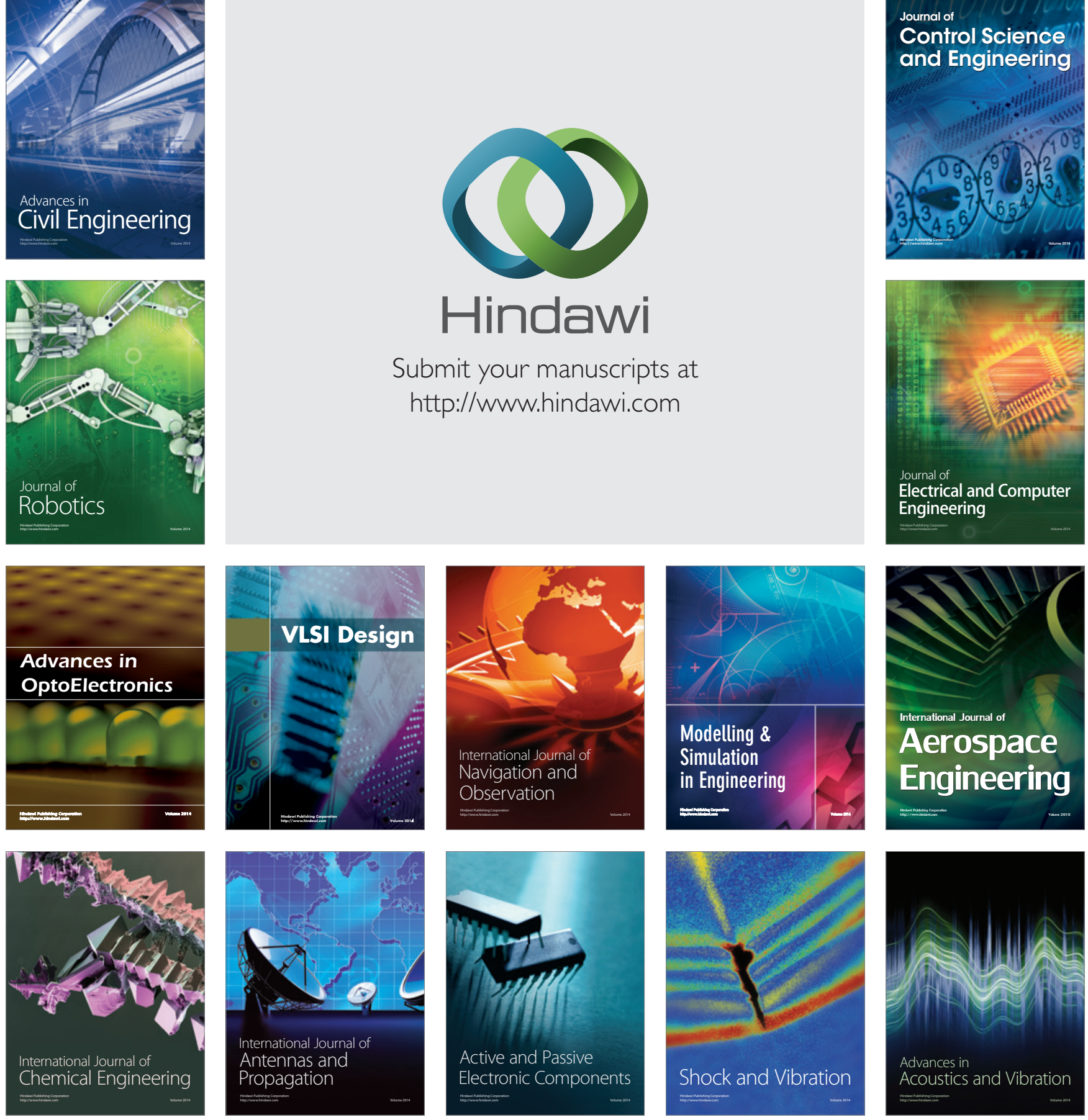